\title{
Economic Implications of Soil Erosion: A methodological framework
}

\author{
Josily Samuel, C A Rama Rao, Raju B M K, Rao K V, Rejani R, Ravi Dupdal, \\ K L Sharma and M Maheshwari. \\ Central Research Institute for Dryland Agriculture (CRIDA) \\ josilysamuel@gmail.com and josily@crida.in
}

\begin{abstract}
Soil erosion has adverse economic and environmental impacts. The economic effects are due to loss of farm income with adverse impact on crop production. There is a need to understand the trade-offs between farm income and soil loss faced by the farmers in making decisions at farm level. There are different methodologies that integrate into a bio-economic model wherein the multi objective linear programming models have focus on the economic aspects and biophysical components. In this study, we tried to examine the status of soil erosion and formulated a methodological frame work for optimising the farm level objectives and their trade-offs for sustainable farming systems.
\end{abstract}

KEYWORDS: Erosion, optimisation, bio-economic model

\section{INTRODUCTION}

Agriculture is known for its multifunctional character. Apart from its productive role it is also a source of income and employment while the benefits from agriculture are not devoid of the negative effects. Most of the rural poor in the developing countries are dependent on resource based subsistence economies. And they live in degraded lands with vulnerable environments. On a farm the several economic activities compete for common resources available, resulting in different level of returns and employment. The levels of various economic activities are interdependent with respect to their returns, resource requirements and availability on the farm. The farmer is faced with multiple trade-offs when deciding on the allocation of the available resources to the competing activities in their farm. Among the various resources land is 
the important limited resource, which shows variation in fertility. The day to day decisions made by the farmer in allocating the resources have implications for future sustainability of the farm system. The major threat facing the sustainability and productivity is soil erosion and the associated nutrient loss through run-off.

Soil erosion, whether induced by water or wind, involves translocation of topsoil from one place to another and represents the most important land degradation problem. (Hein,2007). Determining factors of soil erosion are rainfall, vegetation (cover), topography, soil properties , land slope, and exposure as well as socioeconomic factors like population density and severity of poverty (De Graff, 1993). The extent to which erosion actually reduces yields depends on the types of crops and technologies followed, implying that the crop management system can have an influence on crop yields and the effects of land degradation. Erosion has a non-linear impact on crop yields as the erosion of the top-soil depletes nutrients mostly early in the process and rapidly affect yield and further erosion shows limited impact on the soil. The productivity of land has declined by $50 \%$ due to soil erosion and desertification (Bai et al., 2008). For a realistic study of the economic loss due to erosion and its impact on returns from crop production it is necessary to construct a multiobjective programming model based on a farm management survey. Keeping these in view this paper is an attempt to examine the status and methodological issues to assess the impact of soil erosion. The specific objectives of the study were a (i) To study /review the status of soil erosion and its implications on farm productivity and (ii) to review and formulate methodology to assess the economic impact of soil erosion

\section{METHODOLOGY:}

To proceed, the secondary data on erosion was collected from various published sources. Various studies on the impact of land degradation with special reference to soil erosion were reviewed and data was gathered on impact. The methodologies used to assess and quantify the impact of soil erosion were studied and a methodology to study the economic impact of soil erosion was formulated.

\section{RESULTS AND DISCUSSION :}




\section{Status and implications of erosion}

Table 1. Global extent of human-induced soil degradation

\begin{tabular}{|c|c|c|c|c|}
\hline \multirow[t]{2}{*}{ World regions } & \multirow{2}{*}{$\begin{array}{l}\text { Total land } \\
\text { area }\left(10^{6}\right. \\
\text { ha) }\end{array}$} & \multirow{2}{*}{$\begin{array}{l}\text { Human-induced } \\
\text { soil degradation } \\
\left(10^{6} \mathrm{ha}\right)\end{array}$} & \multicolumn{2}{|c|}{ Soil erosion $\left(10^{6} \mathrm{ha}\right)$} \\
\hline & & & Water & Wind \\
\hline Africa & 2966 & 494 & 227 & 186 \\
\hline Asia & 4256 & 748 & 441 & 222 \\
\hline South America & 1768 & 243 & 123 & 42 \\
\hline $\begin{array}{l}\text { Central } \\
\text { America }\end{array}$ & 306 & 63 & 46 & 5 \\
\hline North America & 1885 & 95 & 60 & 34 \\
\hline Europe & 950 & 219 & 114 & 42 \\
\hline Oceania & 882 & 103 & 83 & 16 \\
\hline World total & 13013 & 1965 & 1094 & 548 \\
\hline
\end{tabular}

Lal,2001

In South Asia annual loss in production is estimated at 36 million tons of cereal equivalent value at US\$ 54,000 million by water erosion and US \$ 1800 million due to wind erosion. On a global scale the annual loss of 75 billion tons of soil costs the world about US \$ 4000 billion per year, approximately US $\$ 70$ per person per year (Eswaran, et al, 2001). As per the estimates of NBSS \&LUP the average loss of top soil due to erosion is 19.6 tonnes per hectares of this $1.39 \%$ is actual nutrient loss in terms of NPK (Reddy, 2003).

Table 2. Land area affected by soil erosion by water and wind in South Asia

\begin{tabular}{|l|l|l|l|}
\hline Country & $\begin{array}{l}\text { Water erosion } \\
(\mathrm{Mha})\end{array}$ & $\begin{array}{l}\text { Wind erosion } \\
(\mathrm{Mha})\end{array}$ & $\begin{array}{l}\text { Total land area } \\
(\mathrm{Mha})\end{array}$ \\
\hline Afganistan & 11.2 & 2.1 & 65.3 \\
\hline Bangladesh & 1.5 & 0 & 14.4 \\
\hline
\end{tabular}




\begin{tabular}{|l|l|l|l|}
\hline Bhutan & 0.05 & 0 & 4.7 \\
\hline India & 32.8 & 10.8 & 328.8 \\
\hline Iran & 26.4 & 35.4 & 163.3 \\
\hline Nepal & 1.6 & 0 & 14.7 \\
\hline Pakistan & 7.2 & 10.7 & 79.6 \\
\hline Sri Lanka & 1.0 & 0 & 6.6 \\
\hline Total & 81.74 & 59.0 & 677.4 \\
\hline
\end{tabular}

$\mathrm{Lal}, 2001$

Onsite productivity losses include both short term and long term effects


,loss of water, additional tillage and loss in time due to delayed sowing

Long-term productivity effects : loss of topsoil, decline in soil structure, decrease in soil organic matter content, tillage erosion

\section{Review of methodology to assess impact of soil erosion}

Among the different approaches used for decision making and resource allocation the economic optimization models are used for their ability to explore different scenarios. The economic optimization models include bio-physical components and 'activities' among the various choices for optimization and it is the case of multiple goal linear programming (MGLP). The essence of management science is manifested in modeling approach; moreover planning methodology to specify optimal use of scare resources is the most important practical approach (Sadeghi, et al., 2005). Nikkami, et al., (2002) used multi objective linear programming to minimize soil erosion and maximize agricultural benefit for Siahroodarea in Damavand watershed, Iran. While Sadeghi et al., (2009) found significant reduction in soil erosion and augmentation in profit from allocating the optimal land uses in Iran.

Singh and Singh (1999) in a case study in Mahi Comand watershed, India, maximized the production and benefit using linear optimization. The results of their study revealed that the application of optimal plan could increase the agricultural productions and net return almost 36 per cent. Amir and Fisher (1999) introduced an optimizing linear model for analyzing 
agricultural production under various water quantities, qualities, timing, prices and pricing policies. Kefi and Yoshino, (2010) found that soil erosion had negative impact on the agricultural productivity and results of optimization showed that total income was reduced by about 17 per cent and the total area under rainfed crops is decreased in the plan. The results also indicate that the farmers try to preserve their land and to decrease the effect of soil erosion by changing their crop husbandry activities. Tittonel, (2007) analysed trade-off between different farmer's objectives and compared with potential resource allocation strategies to achieve them. The adverse environmental effects resulting from hill agriculture can be reduced by opting for multi-objective optimal farm plans, where soil erosion is minimized (Pant and Pandey, 1999).

Opportunities exist to reduce the soil losses induced by crop cultivation on marginal lands, while still achieving food self sufficiency (Lu and Ittersum, 2004). In order to increase productivity and ensure sustainability, it is necessary to understand trade-offs between immediate concerns such as food and cash and also reducing the soil and nutrient losses. These conflicting policy objectives can be either achieved by introduction of new practices or by changing the crop plan, keeping the existing crops and current management practices. The MOLP is employed where in conflicting objectives are simultaneously optimized subject to constraints in order to define an efficient set of solutions (Romero and Rehman, 1989).The impact of soil erosion on productivity can be estimated econometrically or from secondary sources or through biophysical models that simulate the interaction between biophysical factors on productivity.

\section{Methodological Framework}

\section{Data}

Primary data required include resource endowments, cropping pattern, input use and prices, productivity levels and slope of the land are to be obtained from sample farmers from the watershed. This data is used to derive the input coefficients and the availability of different inputs and resources at the farm level. In order to estimate soil loss from the study area secondary data on land use, climatic and soil parameters were collected. The Global Positioning System (GPS) is used get the location specific details of the watershed such as latitude, longitude, elevation, slope etc.,

Sampling design 
Statistical survey design for environmental monitoring falls into basic types like random sampling, systematic sampling and stratified random sampling. In our study stratified sampling was chosen where in a population was divided into sub populations / strata and then random sample were taken from each stratum. For instance survey of effect of erosion can be done by major stratas which can be established in different elevation groups, slope categories, farm sizes, land uses etc.

Study area and sampling

The study area selected was Padmaram watershed in Mahabubnagar District of Andhra Pradesh belonging to Kondrugu mandal (Fig.1). The Padmaram Gram Panchayat having four hamlets namely Padmaram, Laxmidevpally, Elkagudem and Boyagudem. Padmaram watershed area covers the Padmaram and other 3 villages with 530 households. Total watershed area is 859.75 hectares. Stratified random sampling was done. The watershed is divided into three major strata based on the slope / elevation. From each strata sample farmers are chosen randomly. Primary data using a well structured schedule was collected from the sample farmers along with the details on survey number and plot number pertaining to them. 


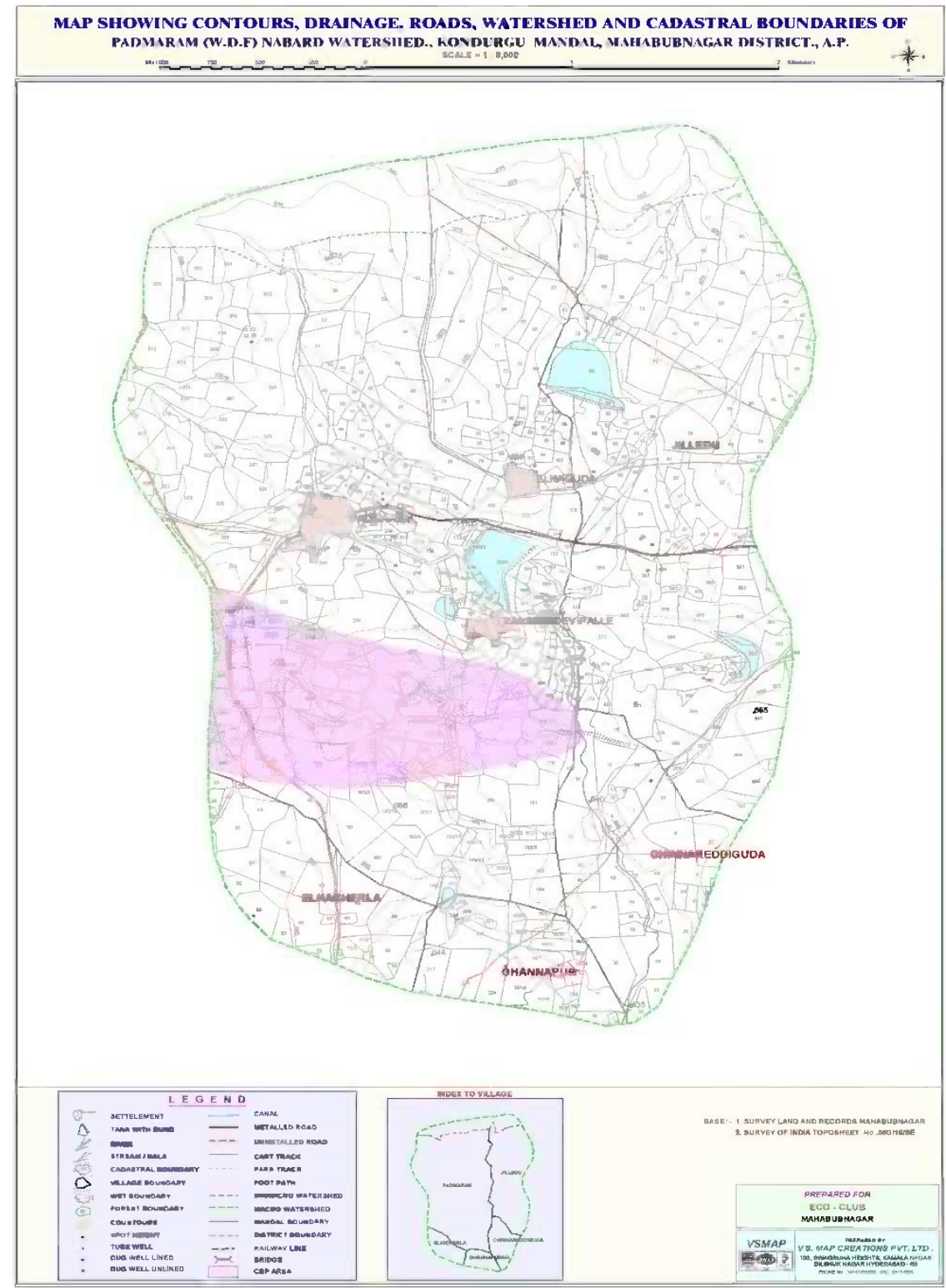

Figure 1. Map of Padmaram watershed

\section{The Bio-economic model: Impact of soil erosion}

The construction of the multi objective programming model is based on farm survey, using the schedule designed to obtain a description of the prevailing farming practices in local farms. The data from the survey would be analyzed to estimate technical and economic indicators of farm management practices. The indicator would include yield, prices for crops from which the 
gross margins, labor requirements, variable costs machinery costs and labour. These would form the basis for the MOLP along the erosion rates of the crops of the locality.

The conflicting objectives under examination would be maximization of net returns/income, minimization of soil erosion etc. This application is based on the constraint method, within which one of the objectives is optimized while the others are specified as constraints (Cohon 1978; Romero and Rehman, 1989). The multi objective programming problem for $\mathrm{p}$ objectives is formulated as follows

$\operatorname{Maximize} \mathrm{Z}\left(\mathrm{x}_{1}, \mathrm{x}_{2}, \ldots, \mathrm{x}_{\mathrm{n}}\right)=\mathrm{Z}\left[\mathrm{Z}_{1}\left(\mathrm{x}_{1}, \mathrm{x}_{2}, \ldots, \mathrm{x}_{\mathrm{n}}\right), \mathrm{Z}_{2}\left(\mathrm{x}_{1}, \mathrm{x}_{2}, \ldots, \mathrm{x}_{\mathrm{n}}\right), \ldots, \mathrm{Zp}\left(\mathrm{x}_{1}, \mathrm{x}_{2}, \ldots, \mathrm{x}_{\mathrm{n}}\right)\right]$

Subject to $\left(\mathrm{x}_{1}, \mathrm{x}_{2}, \ldots, \mathrm{x}_{\mathrm{n}}\right) \in \mathrm{F}_{\mathrm{d}}$, where $\mathrm{F}_{\mathrm{d}}$ is the decision space and $\left(\mathrm{x}_{1}, \mathrm{x}_{2}, \ldots, \mathrm{x}_{\mathrm{n}}\right)$ are the activities.

The problem is converted to constraint problem and objective $\mathrm{Z}$ is arbitrarily selected for maximization. Separate LP problems are formulated as follows

$$
\begin{array}{ll} 
& n \\
\text { Maximize } Z=\sum C_{j} X_{j} \\
j=1 \\
\text { Subject to } \quad n \\
& \sum a_{i j} X_{j} \leq \text { bi, all } i=1 \text { to } n \\
& j=1 \\
& \\
& X_{j} \geq 0
\end{array}
$$

where $C_{j}$ represents the contribution of each activity $\left(X_{j}\right)$ to the objective function and $a_{i j}$ are technical and economic co-efficients for each activity. The trade-offs among the objectives are estimated. These trade-offs reflect the opportunity costs of each objective. The trade-offs would vary with the level of use of each input. The objective variable selected for the study is minimisation of soil loss and maximisation of farm incomes. 


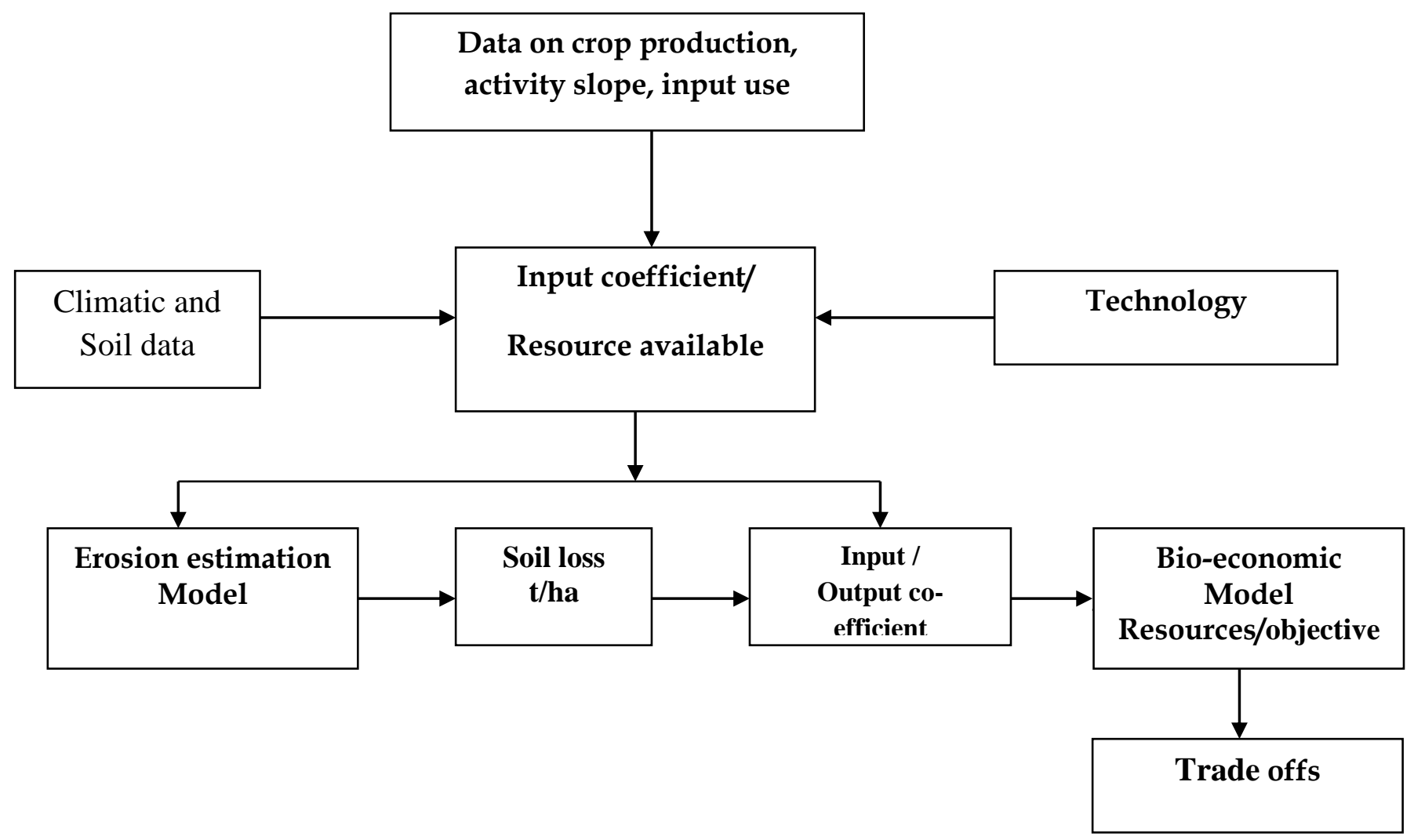

CONCLUSION:

Soil erosion is a wide spread problem affecting agriculture. The watershed optimisation taking into consideration the quantum of erosion for sustainable development is necessary. Erosion affects the agriculture productivity and thereby impacting the income of the farmer. The application of bi-economic optimisation approaches have been recently started due to low efficiency of the system in terms of production. This methodology examines the possibilities of minimising erosion and to maximize the benefits from agriculture. 


\section{REFERENCES}

Amir, I., and Fisher, F.M., 1999. Analysing agricultural demand for water with an optimizing model . Agricultural systems, 61 (1), 45- 56

Bai, Z. G, D.L.Dent, L.Olsson and M.E.S Chaepman, 2008. Proxy global assessment of land degradation. Soil use and management, 24, 223-234

Lu, C.H. Van Ittersum, M.K. 2004. A trade-off analysis of policy objectives for Ansai, the Loess Plateau of China, Agriculture, Ecosystems and Environment, 102 (2004), 235-246

Cohon, J. L. 1978. Multiobjective Programming and Planning. New York:Academic Press.

De Graaff, J., 1993. Soil conservation and sustainable land use: an economic approach. Royal Tropical Institute, Amsterdam, Netherlands. 191 pp.

Eswaran, H., R. Lal and P.F. Reich. 2001. Land degradation: an overview. In: Bridges, E.M., I.D. Hannam, L.R. Oldeman, F.W.T. Pening de Vries, S.J. Scherr, and S. Sompatpanit (eds.). Responses to Land Degradation. Proc. 2nd. International Conference on Land Degradation and Desertification, Khon Kaen, Thailand. Oxford Press, New Delhi, India.

Hein, L. 2007. Assessing the costs of land degradation: A case study for the Puentes catchment, southeast Spain. Land Degradradation and Development., 18:631-642, 2007.

Pant, K.P. and Pandey, V.K 1999. Minimising environmental problems in hill agriculture of Nepal through multiobjective farm planning. Ind.Jn. of Agri.Econ. Vol. 54. No.1 JanMarch, 1999

Kefi, M., Yoshino, K., 2010. Evaluation of the Economic Effects of Soil Erosion Risk on Agricultural Productivity using Remote Sensing: Case of Watershed in Tunisia, 
International Archives of the Photogrammetry, Remote Sensing and Spatial Information Science, Volume XXXVIII, Part 8, Kyoto Japan 2010

Nikkami, D., Elektorowicz, M., Mehuys, G.R., 2002. Optimizing the management of Optimal Crop Planning: a Case Study of Mahi Command, Indian Journal of Soil Conservation, 27(2): 157-152

Romero, C. And Rehman T. 1989. Multiple criteria analysis for agricultural decisions, Elsevier Publishing co, Amsterdam.

Sadeghi, S.H.R., Jalili, Kh., Nikkami, D., 2005. Land use planning: a practical approach in soil erosion control. In: Proceedings of International Conference on Human Impacts on Soil Quality Attributes, Isfahan, September 12-16, p. 5.

Sadeghi, S.H.R., Jalili, Kh., Nikkami, D., 2009 . Land use optimisation in watershed scale. land use policy, 26 (2009), 186-193

Singh, A.K. and Singh, J.P., 1999. Production and Benefit Maximization Through soil erosion. Water Qual. Res. J. Canada 37 (3), 577-586.

Reddy, V. R. 2003. Land degradation in India - Extent, costs and determinants. Economic and Political Weekly, November 1, 2003. 


\section{Title: Economic Implications of Soil Erosion: A methodological framework}

Authors: Josily Samuel ${ }^{\mathrm{a}}$, C A Rama Raoc, Raju B M K ${ }^{\mathrm{b}}$, Rao K V ${ }^{\mathrm{c}}$, Rejani R ${ }^{\mathrm{b}}$, Ravi Dupdala K L Sharma ${ }^{\mathrm{c}}$ and M Maheshwari ${ }^{\mathrm{d}}$.

Affliation: ${ }^{\mathrm{a}}$ Scientist, ${ }^{\mathrm{b}}$ Senior Scientist, ${ }^{\mathrm{c}}$ Principal Scientist and ${ }^{\mathrm{d}}$ Director ,Central Research Institute for dryland Agriculture (CRIDA), Santhosnagar, Hyderabad

E-Mail: josily@crida.in, josilysamuel@gmail.com

This paper is an output from the institute project 'Economic implications of soil erosion: A farm level study' 